\title{
The semi-Markov model of the process of appearance of sea-going ship propupsion system ability and inability states in application to determining the reliablity of these systems
}

\author{
Jerzy Girtler, Prof., \\ Gdansk University of Technology, Poland
}

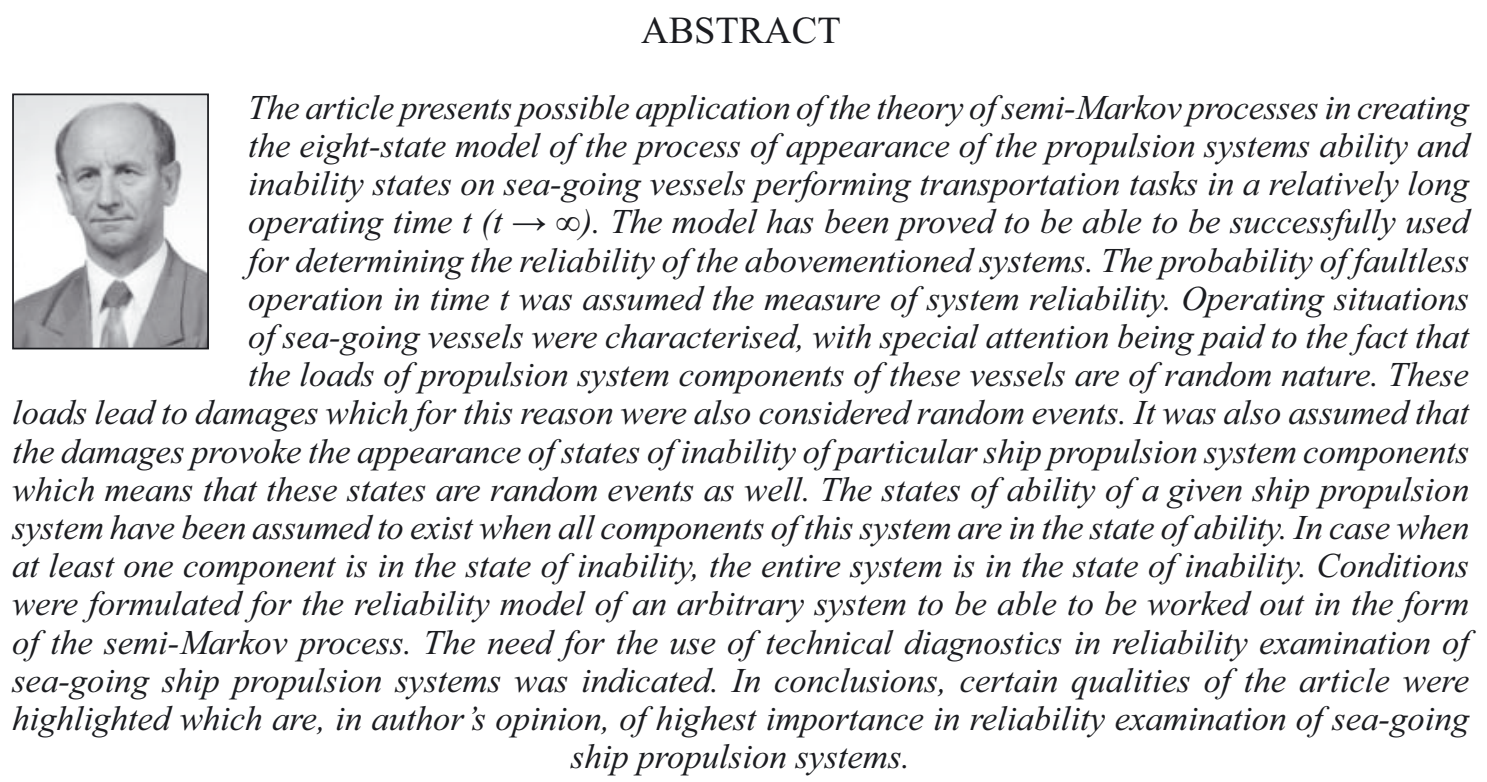

Key words: reliability, semi-Markov process, state of ability, state of inability, sea-going ship, ship propulsion system

\section{INTRODUCTION}

Sea-going ships perform transportation tasks in remarkably different weather and sea conditions, which generally depend on: wind force and direction, sea undulation level (height, length and direction of waves), speed and direction of sea currents, level of underwater hull section overgrowing with algae and crustaceans, ship over-icing, and type of the water region in which the ship sails while performing the transportation task [9, 10, 19]. Extremely unfavourable conditions of ship operation have place when the ship performs the transportation task in storm: at the wind (hurricane) flowing with the speed which can exceed $29 \mathrm{~m} / \mathrm{s}$ in extreme cases and reveal a heavily destructive potential, and on the sea with waves of over $300 \mathrm{~m}$ in length and $10 \mathrm{~m}$ in height. What is more, in such cases the hurricane carries such huge amounts of water dust with the air that the visibility is practically equal to zero. The situation at sea which corresponds to slightly better conditions of ship sailing is shown in Fig. 1. It has place when waves of over $5 \mathrm{~m}$ in height and $100 \mathrm{~m}$ in length become steep and the whitecaps on wave crests start arranging in strips. This state of sea is characterised by loud noise of breaking waves which can be heard even from a large distance and is additionally intensified by extremely strong wind having the speed over $12 \mathrm{~m} / \mathrm{s}$.

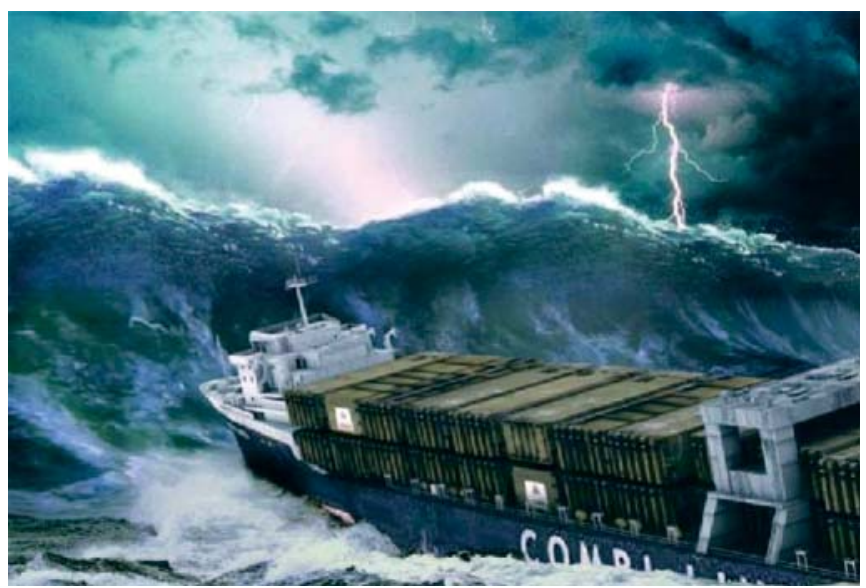

Fig. 1. Situation at sea in storm conditions in which the container ship performs the transportation task (the situation which is at least dangerous) 
Performing transportation tasks by any ship in the conditions of strong undulation of surface sea layers (Fig. 1) creates unfavourable conditions for operation of all power conversion system equipment installed on the ship, in particular for its propulsion system with the main engine. This sometimes causes damage to system components, most frequently the main engine (Fig. 2) which as a rule leads to sea disaster. It is possible to prevent such unfavourable and even dangerous events once we know, among other factors, the probability of occurrence of such random events considered the states of ability and inability of the ship propulsion system. To assess those probabilities we need a relevant model of the process of appearance of the abovementioned states. And to work out this model, in turn, we should identify sea and weather conditions in which transportation tasks are performed by ships, and attribute relevant reliability states of ship propulsion systems to those conditions.

\section{SEA AND WEATHER CONDITIONS DURING SHIP VOYAGES AND RELIABILITY STATES OF SHIP PROPULSION SYSTEMS}

The sea and weather conditions in which the transportation tasks are performed by sea-going ships may differ considerably. In the temperate climate, surface layers of the sea water are, as a rule, turbulent in spring and autumn. Impetuous action of the undulated sea on the ship hull is additionally intensified by strong wind, the gusts of which can reach $24.4 \mathrm{~m} / \mathrm{s}$ (strong gale, 9 in Beaufort scale), $28.4 \mathrm{~m} / \mathrm{s}$ (whole gale, 10 in Beaufort scale), $32.5 \mathrm{~m} / \mathrm{s}$ (violent storm, 11 in Beaufort scale), or as much as $36.6 \mathrm{~m} / \mathrm{s}$ (hurricane, 12 in Beaufort scale) [10]. Such a situation is a threat to ship's safety and frequently leads to its sinking. As a rule, the ship sinks when one of some components of its main propulsion system are damaged. As a result of this damage, power transmission to the screw propeller (7) is stopped and the thrust force $(T)$ and the driving force component $\left(T_{N}\right)$ which balances the resistance $\left(\mathrm{R}_{\mathrm{x}}\right)$ and allows the ship to sail with speed v (Fig. 2) are not generated any longer. Generally, the force $\mathrm{T}_{\mathrm{N}}$, along with the force acting on the rudder, secure relevant course stability (steering quality) of the ship.

The forces $\mathrm{R}_{\mathrm{ha}}$ and $\mathrm{R}_{\mathrm{G} 1}$ which act at a right angle to the lever arm a generate the ship trim by the stern, which is additionally increased by forces $T_{N}$ and $R_{x}$ acting at a right angle to the arm b. All this leads to sometimes heavy reduction of the driving
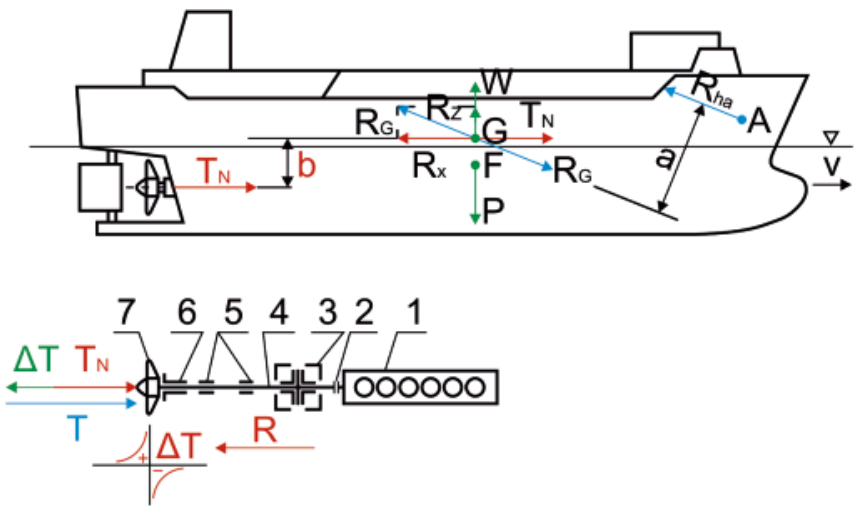

Fig. 2. Scheme of forces and moments acting on the ship: $\boldsymbol{T}$-thrust force, $\boldsymbol{T}_{\boldsymbol{N}}-$ driving force, $\Delta \boldsymbol{T}-$ thrust deduction, $\boldsymbol{R}=\boldsymbol{R}_{\boldsymbol{x}}$ - overall ship hull resistance which is balanced by force $T_{N}, \boldsymbol{R}_{\text {ha }}-$ resultant force of all hydroand aerodynamic forces acting on the ship, $\boldsymbol{R}_{-}-$hydro- and aerodynamic

lift, $\boldsymbol{P}$ - ship weight, $\boldsymbol{W}$ - ship's buoyancy force, $\boldsymbol{G}$ - ship's centre of gravity,

$\boldsymbol{F}$-ship's centre of buoyancy, $\boldsymbol{a}$-arm of action of forces $R_{h a}$ and $R_{G l}$

$\boldsymbol{b}$-arm of action of thrust generating forces $T_{N}$ and $R_{x}, \boldsymbol{1}$ - main engine,

2 - coupling, 3 - thrust bearing with (thrust) shaft, 4 - propeller shaft, 5 -radial bearings, $\mathbf{6}$-stuffing-box, 7 -screw propeller force $\left(\mathrm{T}_{\mathrm{N}}\right)$, which in turn remarkably decreases the course stability of the ship and, finally, its safety.

Many sea disasters taking the form of: 1) ship's running aground on rocky or sandy shallows, or 2) ship's collision with underwater rock or coral reef, or 3) ship's turn over during the storm, or, finally, 4) collision of two ships, are likely to take place when the main engines cannot be loaded, due to their bad technical state, within the entire load range for which they were preconditioned in the design and production process (Fig. 3). This situation is a threat to ship's stability, and the ship's voyage performed in such conditions at heavy sea frequently end with a disaster.

One of main causes of sea disasters is worsened technical condition of ship propulsion systems, especially the main engines used for ship driving. Bad technical condition of these systems is the reason why they cannot be loaded with full load, and consequently a sufficiently large thrust force $\mathrm{T}$ cannot be generated by the screw propeller (Fig. 2). In such cases, even the maximum rudder deflection is not sufficient to generate forces which will compensate the action of wind and undulated sea. As a consequence, the ship firstly loses its steering qualities (course stability) and cannot move any longer in the assumed direction, and then it loses its transverse stability. The appearance of the backstay wind along with the following waves during strong sea undulation makes the ship turn over, as a rule [9].

The course stability can be kept by the ship only when the main engine can be loaded within the entire load range to which it was preconditioned in the design and production phase, i.e. within the working area 1-E-2-3-1 limited by external speed characteristics: $\mathrm{h}_{\max }=\mathrm{idem}$ and $\mathrm{h}_{\min }=\mathrm{idem}$, and controller speed characteristics $\mathrm{NR}_{\max }=$ idem and $\mathrm{NR}_{\min }=$ idem in Fig. 3 $[16,18]$. If the propulsion system can be loaded within the above range, we can assume that the system is in the state of ability. If it can be loaded only within a limited range, for instance along an external main engine characteristic $\mathrm{h}_{\text {nom }}=$ idem or $\mathrm{h}_{\mathrm{t}}=\mathrm{idem}$ (Fig. 3), and, simultaneously, with the power much smaller than $\mathrm{N}_{\mathrm{en}}$ or $\mathrm{N}_{\mathrm{et}}$, we have to assume that the propulsion system is in the state of inability. This conclusion results from the fact that when the system is loaded within a limited range, for instance along the line segment A-D of the controller characteristic (Fig. 3), the generated thrust force $\mathrm{T}$ (Fig. 2) and its component $\mathrm{T}_{\mathrm{N}}$ (being the driving force) are not large enough to balance, in storm conditions, the force $R_{x}$ which is the total hull resistance at ship's speed v. Nevertheless in good weather conditions, safe ship sailing along the line segment A-B or even A-C of the abovementioned characteristic is still quite possible. Obviously, the state of ability of the propulsion system can be defined in another way, for instance assuming that it is reached when the main engine can be loaded in accordance with the engine speed characteristics which allow it to fulfil one of the following criterion functions (Fig. 3): optimal overall propulsion efficiency $\eta_{\mathrm{n}(\mathrm{ppt})}$, optimal overall engine efficiency $\eta_{\text {o(opt) }}$, or optimal driving efficiency $\xi_{\text {o(opt })}[16,18]$. Controlling the engine operation according to the curve of optimal engine efficiency $\eta_{\mathrm{o}(\mathrm{opt})}$ makes it possible to reach the minimal specific consumption of the fuel (heavy oil or diesel oil), while controlling it in accordance with the curve of optimal driving efficiency $\xi_{\text {o(opt) }}$ leads to the minimal effective power of the engine for the a priori assumed speed of ship motion. Clearly, in this case the specific fuel consumption is larger than when the engine operates according to the curve $\eta_{\text {o(opt) }}$. It is also clear that controlling the engine operation should consist in such selection of injection pump setting $\mathrm{h}=$ idem and the screw pitch setting $(\mathrm{H} / \mathrm{D})=$ idem, that the optimal overall propulsion efficiency $\eta_{\text {n(opt) }}$ is obtained for given external conditions WZ (sailing conditions), and not only the 


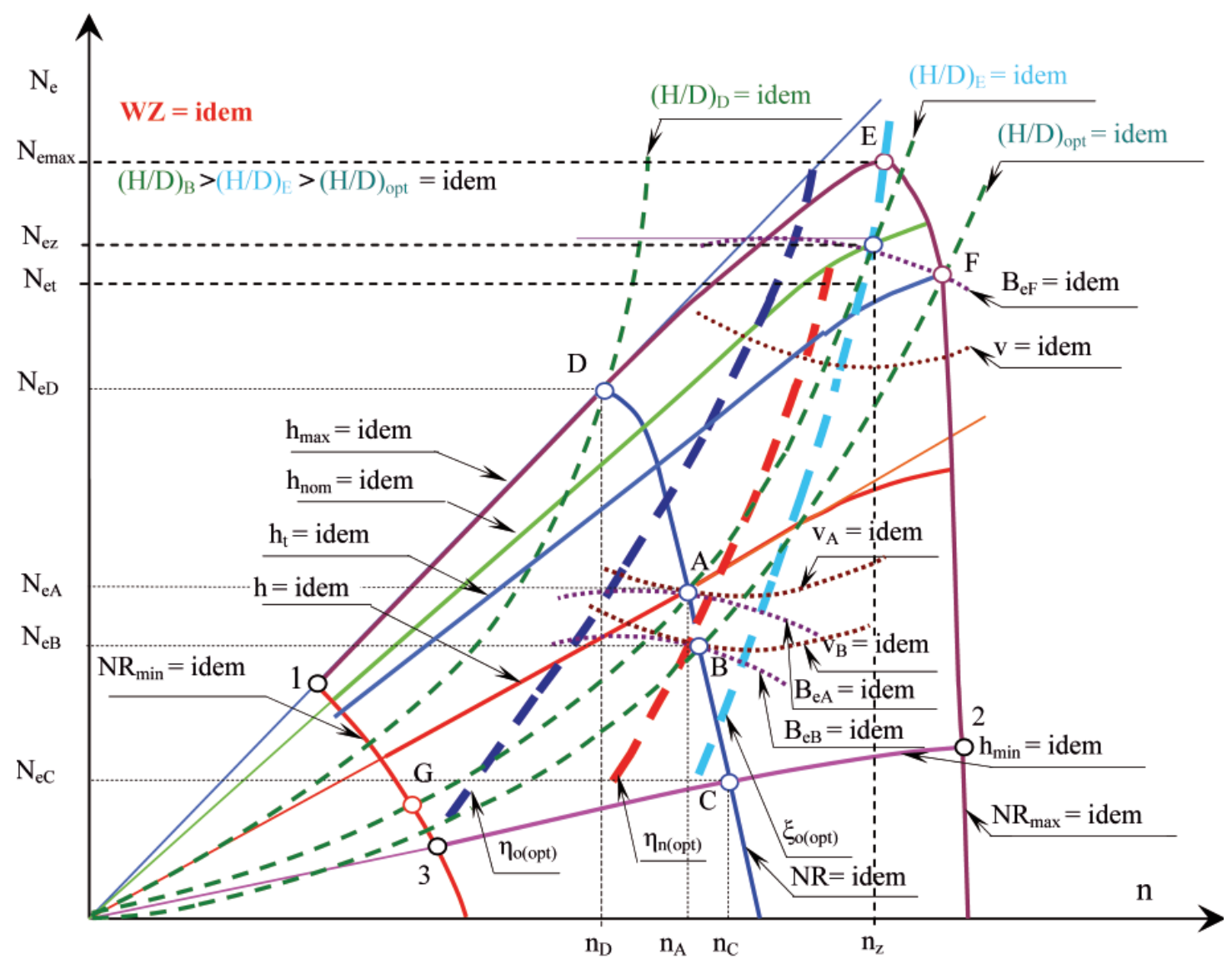

Fig. 3. Sample motion characteristic of the propulsion system for $W Z=i d e m: \boldsymbol{H} / \boldsymbol{D}$ - adjustable blade propeller pitch coefficient, $(\boldsymbol{H} / \mathbf{D})_{\text {opt }}-$ optimal adjustable blade propeller pitch coefficient, $\boldsymbol{W Z}$ - external conditions of ship motion, $\boldsymbol{B}_{\boldsymbol{e}}-$ engine's diesel oil consumption per hour, $\boldsymbol{B}_{\text {eA }}-$ diesel oil consumption per hour at point $A$ of engine operation, $\boldsymbol{B}_{e B}-$ diesel oil consumption per hour at point $B$ of engine operation, $\boldsymbol{B}_{e F}-$ diesel oil consumption per hour at point $F$ of engine operation, $\boldsymbol{v}$-ship speed, $\boldsymbol{v}_{A}$-ship speed when the engine works at point $A$, $\boldsymbol{v}_{B}-$ ship speed when the engine works at point $B$, $\boldsymbol{N R}$ - rotational speed controller setting, $\boldsymbol{N R}_{\max }$ - maximal rotational speed controller setting, $\boldsymbol{N R}_{\text {min }}$ - minimal rotational speed controller setting, $\boldsymbol{h}_{\text {max }}$ - maximal fuel bar setting, $\boldsymbol{h}_{\text {nom }}$ - nominal fuel bar setting, $\boldsymbol{h}_{\min }-$ minimal fuel bar setting, $\boldsymbol{h}_{\boldsymbol{t}}-$ fuel bar setting which enables obtaining continuous effective power $\left(N_{e}\right), \boldsymbol{h}$-fuel bar setting, $\boldsymbol{N}_{e}$-effective power of the engine, $\boldsymbol{N}_{e z}$ - nominal effective power, $\boldsymbol{N}_{e t}-$ continuous effective power, $\boldsymbol{N}_{e A}-$ effective power at point $A$ of engine operation, $\boldsymbol{N}_{e B}$-effective power at point $B$ of engine operation, $\boldsymbol{N}_{e C}-$ effective power at point $C$ of engine operation,

$\boldsymbol{N}_{e D}$ - effective power at point D of engine operation, $\boldsymbol{n}$-rotational speed of the engine, $\boldsymbol{n}_{\boldsymbol{n}}-$ nominal rotational speed, $\boldsymbol{n}_{\boldsymbol{A}}-$ rotational speed at point $A$ of engine operation, $\boldsymbol{n}_{C}$ - rotational speed at point $C$ of engine operation, $\boldsymbol{n}_{\boldsymbol{D}}$-rotational speed at point $D$ of engine operation,

$\boldsymbol{\eta}_{\text {o(opt })}$ - optimal overall engine efficiency, $\boldsymbol{\eta}_{\boldsymbol{n}(\text { opt })}$ - optimal overall propulsion efficiency, $\boldsymbol{\xi}_{\text {o(opt })}$ - optimal driving efficiency

optimal overall engine efficiency $\eta_{\mathrm{o}(\mathrm{opt})}$ nor optimal driving efficiency $\xi_{\mathrm{o}(\mathrm{opt})}[18]$. However, being of high importance for the realisation of the rational engine operation process in normal conditions, such methods are not applicable when the ship safety is under threat in storm conditions, as in those cases (Fig. 3) the engine is to be loaded not only with the full nominal effective power $\left(\mathrm{N}_{\mathrm{ez}}\right)$ at the nominal speed $\left(\mathrm{n}_{\mathrm{z}}\right)$, but also with larger powers, including the maximal power $\left(\mathrm{N}_{\mathrm{emax}}\right)$ (point E).

The above analysis reveals that the main engine (1) transmitting mechanical energy to the screw propeller (7) can be loaded at different effective powers $\left(\mathrm{N}_{\mathrm{e}}\right)$ and rotational speeds (n). Possible ways of main engine loading are shown in Fig. 3, which illustrates a sample motion characteristic of the ship propulsion system. It is noteworthy that the load reveals a random nature, which causes the wear of the engine and other propulsion system components, and leads to propulsion system damages, considered the random events.

Therefore of high importance is the knowledge on ship propulsion system reliability, which can be interpreted in a descriptive sense as the system property which secures its ability to be loaded within the entire engine performance range (Fig. 3) in a defined time [2,3]. At the same time in the normative sense, the system reliability can be calculated as the probability of maintaining the ability to be loaded within the entire engine performance range in certain time and given ship operation conditions.

It results from the proposed interpretation of ship propulsion system reliability that the reliability of the system of this type is maintained when it can be loaded within the entire range of loads to which it was preconditioned in the design and production phase. With the reference to $[3,4]$ we can state that this means that the reliability of the main engine and entire propulsion system requires maintaining the state of its ability $\left(\mathrm{s}_{0}\right)$. In case the engine or another component of the ship propulsion system cannot be loaded within the entire load range due to their worsened technical condition, we have to assume that the system is in the state of inability $\left(\mathrm{s}_{\mathrm{i}}, \mathrm{i}=1,2\right.$, $\ldots, 7)[16,18]$.

The reliability states and time intervals of their duration can be recognised using relevant diagnostic systems $(S D G)$, such as for instance: CoCoS (Computer Controlled Surveillance System) produced by $M A N$, or CBM (Condition-Based Maintenance) produced by Wartsila $[22,23]$ for marine engine diagnostics.

The above considerations reveal that changes of the both technical and energetic state of the propulsion systems of sea-going ships (including also their individual components) are random events. These changes, when analysed during the operation of systems of this type, can be considered the 
realisations having the form of stochastic processes which are discrete in states and continuous in time. Worsening of the technical condition of these systems is mainly affected the conditions in which they work $[5,16,18]$.

These conditions can change from most favourable to most difficult $[9,10,16,18]$. In this situation the use of technical diagnostics with relevant diagnosing systems (SDG) is necessary. SDG's are needed for identifying technical states of the propulsion systems being the diagnosed systems (SDN). They are also needed for recording times when these states appear and time intervals of their duration. The task consists in determining the states which compose the set:

$$
\mathrm{S}=\left\{\mathrm{s}_{0}, \mathrm{~s}_{1}, \mathrm{~s}_{2}, \mathrm{~s}_{3}, \mathrm{~s}_{4}, \mathrm{~s}_{5}, \mathrm{~s}_{6}, \mathrm{~s}_{7}\right\}
$$

having the following interpretation (Fig. 2):

- $\mathrm{s}_{0}-$ state of ability of the propulsion system, which lasts when the main engine (and, consequently, all other system components) can be loaded within the entire range to which the system was preconditioned in the design and production phase,

- $\mathrm{s}_{1}, \mathrm{~s}_{2}, \mathrm{~s}_{3}, \mathrm{~s}_{4}, \mathrm{~s}_{5}, \mathrm{~s}_{6}, \mathrm{~s}_{7}$ - states of inability of the system, which appear and last when: the main engine, the coupling, the thrust bearing, the propeller shaft, the propeller shaft bearings, and/or the propeller shaft screw propeller stuffingbox cannot be loaded within the entire range, although they can be loaded within a limited range.

Additionally, recording the times $\tau_{\mathrm{j}}(\mathrm{j}=0,1,2, . ., \mathrm{n})$ of the appearance of states $s_{i}(i=0,1,2, \ldots, 7)$ and time intervals of their duration $\mathrm{t}_{\mathrm{j}}(\mathrm{j}=0,1,2, . ., \mathrm{n})$ makes it possible to use the theory of semi-Markov processes for working out the semiMarkov model of the process of state changes $s_{i} \in S(i=0,1$, $2, \ldots, 7)$. This model is necessary for determining the reliability of the analysed propulsion systems.

\section{THE SEMI-MARKOV MODEL OF CHANGES OF TECHNICAL STATES OF SHIP PROPULSION SYSTEMS}

The semi-Markov model of changes of the technical state of an arbitrary propulsion system provides opportunities for determining its reliability taking into account both preventive services oriented on protecting against damages, and those forced by the damages. Both types of services are needed for system regeneration. The regeneration of the system takes place after each service, either preventive or forced. In order to determine the reliability of the ship propulsion system, the semi-Markov model of the process of changes of its technical states (in the reliability aspect) can be presented in the form of the semi-Markov process $\{\mathrm{W}(\mathrm{t}): \mathrm{t} \geq 0\}$ with the set of states $\mathrm{S}=\left\{\mathrm{s}_{0}, \mathrm{~s}_{1}, \mathrm{~s}_{2}, \mathrm{~s}_{3}, \mathrm{~s}_{4}, \mathrm{~s}_{5}, \mathrm{~s}_{6}, \mathrm{~s}_{7}\right\}$ (1). Changes of the above named states $\mathrm{s}_{\mathrm{i}}(\mathrm{i}=0,1,2, \ldots, 7)$ take place in consecutive times $\mathrm{t}_{\mathrm{n}}(\mathrm{n} \in \mathrm{N})$. In time $\mathrm{t}_{0}=0$ the system is in the state $\mathrm{s}_{0}$ which lasts until the damage of any system component takes place, while the states $\mathrm{s}_{\mathrm{i}}(\mathrm{i}=1,2, \ldots, 7)$ last until the damaged component is regenerated. The system is damaged when any of its components is damaged, which means that the reliability structure of the propulsion system is a series structure. As a consequence, the state $\mathrm{s}_{0}$ exists when all components of the propulsion system are new, or the degree of their wear is so low that the system can be loaded within the entire range to which it was preconditioned in the design and production phase. At the same time the states $\mathrm{s}_{\mathrm{i}}(\mathrm{i}=1,2, \ldots, 7)$ take place when the abovementioned propulsion system components (Fig. 2) are in the condition which make it impossible to use the system within the entire range of loads. These states are recognised by relevant diagnosing systems (SDG) in time intervals between consecutive preventive services of the system. Taking into account this situation in the phase of propulsion system operation requires a probabilistic description of the process of its state changes $s_{i}(i=0,1,2,3$, $\ldots, 7)$ including the probability of the appearance of these states in particular times $\mathrm{t}_{0}, \mathrm{t}_{1}, \ldots, \mathrm{t}_{\mathrm{n}-1}, \mathrm{t}_{\mathrm{n}}$ of system operation.

It is possible to construct the semi-Markov model of a real process of ship propulsion system state changes, because these states can be defined in such a way that the duration time of the state existing at time $\tau_{\mathrm{n}}$ and the state which can be obtained at time $\tau_{\mathrm{n}+1}$ do not depend stochastically on earlier states and time intervals of their duration. The semi-Markov model $\{\mathrm{W}(\mathrm{t}): \mathrm{t} \geq 0\}$ of the real process of reliability state changes in the phase of propulsion system operation was constructed based on the theory of semi-Markov processes. The proposed model is characterised by the following properties [12, 13, 15, 17]:

1) the Markov condition is met which says that the future evolution of the process of operational changes of ship propulsion system states for which the semi-Markov model was constructed depends only on the system state at a given time, and not on the past system operation, consequently the future of this system depends on the present and not on the past,

2) random variables: $T_{i}$ which represents the duration time of the state $s_{i}$ irrespective of the fact which state will be the next, and $\mathrm{T}_{\mathrm{ij}}$, which represents the duration time of the state "s, given that the next state of this process is the state , $\mathrm{s}_{\mathrm{j}}$, , have distributions different than the exponential distribution.

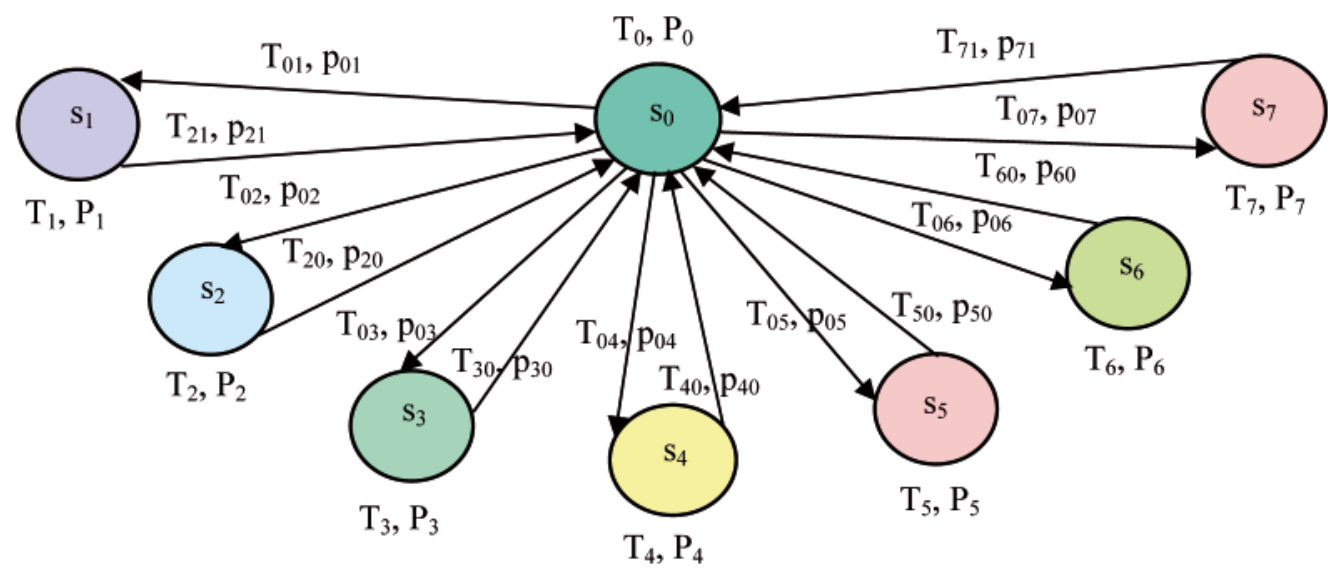

Fig. 4. Graph of state changes in process $\{W(t): t \geq 0\}: s_{0}$ - state of ability of the propulsion system, $s_{1}-$ state of inability of the main engine, $s_{2}-$ state of inability of the coupling, $s_{3}$ - state of inability of the thrust bearing, $s_{4}$-state of inability of the propeller shaft, $s_{5}-$ state of inability of the propeller shaft bearings, $s_{6}$-state of inability of the propeller shaft stuffing-box, $s_{2(7)}$-state of inability of the screw propeller, $T_{i}, P_{i}(i=0,1, \ldots, 7)-$ times and probabilities of propulsion system existence in states $s_{i} \in S(i=0,1, \ldots, 7), T_{i j}, p_{i j}$-times and probabilities of propulsion system existence in states $s_{i} \in S(i=0,1, \ldots, 7)$ given that the next system state is $s_{j}, j=0,1, \ldots, 7 ; i \neq j$ 
Modelling which resulted in the construction of the semi-Markov model of changes of ship propulsion system states took into account the results of the analysis of changes of these states $[1,3,10,18,23]$. These states were recognised as essential in the examination of a real process of their appearance, observed in the system operation phase.

The empirical investigations have proved that we can assume that the state of an arbitrary propulsion system, including that shown in Fig. 2 in the form of a functional scheme, at time $t_{n+1}$ and the time interval of duration of the state reached at earlier time $t_{n}$ do not depend on states taking place at times $t_{0}, t_{1}, \ldots, t_{n-1}$ and their duration times. Therefore the process $\{W(t): t \geq 0\}$ is the semi-Markov process $[1,2,5,6,7,8,11,12,16,17]$. The graph of state changes in this process is shown in Fig. 4.

The initial distribution of this process is the following:

$$
P\left\{W(0)=s_{i}\right\}=\left\{\begin{array}{l}
1 \text { for } i=0 \\
0 \text { for } i=1,2, \ldots, 7
\end{array}\right.
$$

while the functional matrix has the form:

$$
\mathbf{Q}(\mathbf{t})=\left[\begin{array}{cccccccc}
0 & \mathrm{Q}_{01}(\mathrm{t}) & \mathrm{Q}_{02}(\mathrm{t}) & \mathrm{Q}_{03}(\mathrm{t}) & \mathrm{Q}_{04}(\mathrm{t}) & \mathrm{Q}_{05}(\mathrm{t}) & \mathrm{Q}_{06}(\mathrm{t}) & \mathrm{Q}_{07}(\mathrm{t}) \\
\mathrm{Q}_{10}(\mathrm{t}) & 0 & 0 & 0 & 0 & 0 & 0 & 0 \\
\mathrm{Q}_{20}(\mathrm{t}) & 0 & 0 & 0 & 0 & 0 & 0 & 0 \\
\mathrm{Q}_{30}(\mathrm{t}) & 0 & 0 & 0 & 0 & 0 & 0 & 0 \\
\mathrm{Q}_{40}(\mathrm{t}) & 0 & 0 & 0 & 0 & 0 & 0 & 0 \\
\mathrm{Q}_{50}(\mathrm{t}) & 0 & 0 & 0 & 0 & 0 & 0 & 0 \\
\mathrm{Q}_{60}(\mathrm{t}) & 0 & 0 & 0 & 0 & 0 & 0 & 0 \\
\mathrm{Q}_{70}(\mathrm{t}) & 0 & 0 & 0 & 0 & 0 & 0 & 0
\end{array}\right]
$$

The functional matrix $\mathbf{Q}(\mathbf{t})$ represents the model of reliability state changes of the ship propulsion system with the functional scheme shown in Fig. 2. Non-zero elements $\mathrm{Q}_{\mathrm{ij}}(\mathrm{t})$ of the matrix $\mathbf{Q}(\mathbf{t})$ depend on distributions of random variables $\mathrm{T}_{\mathrm{i}}(\mathrm{i}=0,1$, $2, \ldots, 7)$, which are the time intervals when the process $\{\mathrm{W}(\mathrm{t}): \mathrm{t} \geq 0\}$ is in particular states $\mathrm{s}_{\mathrm{i}} \in \mathrm{S}(\mathrm{i}=0,1, \ldots, 7)$. Elements of the functional matrix $\mathbf{Q}(\mathbf{t})$ are the probabilities of transition of the abovementioned process from state $s_{i}$ to state $s_{j}\left(s_{i}, s_{j} \in S\right)$ in time not longer than $\mathrm{t}$. These probabilities are defined in the following way $[11,12]$ :

$$
\mathrm{Q}_{(\mathrm{ij})}(\mathrm{t})=\mathrm{P}\left\{\mathrm{W}\left(\tau_{\mathrm{n}+1}\right)=\mathrm{s}_{\mathrm{j}}, \tau_{\mathrm{n}+1}-\tau_{\mathrm{n}}<\mathrm{t} \mid \mathrm{W}\left(\tau_{\mathrm{n}}\right)=\mathrm{s}_{\mathrm{i}}\right\}=\mathrm{p}_{\mathrm{ij}} \mathrm{F}_{\mathrm{ij}}(\mathrm{t})
$$

where:

$\mathrm{p}_{\mathrm{ij}} \quad$ - probability of uniform Markov chain transition in one step;

$\mathrm{p}_{\mathrm{ij}}=\mathrm{P}\left\{\mathrm{Y}\left(\tau_{\mathrm{n}+1}\right)=\mathrm{s}_{\mathrm{j}} \mid \mathrm{Y}\left(\tau_{\mathrm{n}}\right)=\mathrm{s}_{\mathrm{i}}\right\}=\lim _{\mathrm{tim}} \mathrm{Q}_{\mathrm{ij}}(\mathrm{t})$;

$\mathrm{F}_{(\mathrm{ij})}(\mathrm{t})$ - distribution function of rando ${ }^{\mathrm{t}} \vec{\infty}_{\mathrm{ij}}$ variable $\mathrm{T}_{(\mathrm{ij})}$ representing the time when the process $\{\mathrm{W}(\mathrm{t})$ : $\mathrm{t} \geq 0\}$ is in state $\mathrm{s}_{\mathrm{i}}$ given that the next state is $s_{j}$.

Since the functional matrix $\mathbf{Q}(\mathbf{t})$ (3) is the stochastic matrix, then the matrix $\mathbf{P}(7)$ of the probabilities of transitions of the Markov chain placed into this process consists of terms which are $[1,3,4]$ the probabilities $\mathrm{p}_{\mathrm{ij}}: \mathrm{p}_{00}=0, \mathrm{p}_{\mathrm{i} 0}=\mathrm{Q}_{\mathrm{i} 0}(\mathrm{t})=1(\mathrm{i}=1,2$, $\ldots, 7)$ and $\mathrm{p}_{0 \mathrm{j}}=\mathrm{Q}_{0 \mathrm{j}}(\mathrm{t})(\mathrm{j}=1,2, \ldots, 7)$, for $\mathrm{i} \neq \mathrm{j}$.

The process $\{\mathrm{W}(\mathrm{t}): \mathrm{t} \geq 0\}$ is irreducible $[1,3,4]$ and the random variables $\mathrm{T}_{(\mathrm{ij})}$ have limited and positive expected values. Therefore its limiting distribution $[11,12]$

has the following form [12]:

$$
\begin{gathered}
P_{j}=\lim _{t \rightarrow \infty} P_{i j}(t)=\lim _{t \rightarrow \infty} P\left\{W(t)=s_{j}\right\} \\
s_{j} \in S(j=0,1, \ldots, 7)
\end{gathered}
$$

$$
P_{j}=\frac{\pi_{j} E\left(T_{j}\right)}{\sum_{l=0}^{7} \pi_{1} E\left(T_{1}\right)}
$$

The probabilities $\pi_{j}(j=0,1,2, \ldots, 7)$ in formula (6) are the limiting probabilities of the Markov chain placed into the process $\{W(t): t \geq 0\}$, while $E\left(T_{j}\right)$ and $E\left(T_{1}\right)$ are the expected values of the random variables $T_{j}$ and $T_{1}$, respectively, representing time intervals spent by the propulsion system in states $s_{j}$ and $s_{1}$ independently on what the next state is. Determining the limiting distribution (6) requires solving the system of equations with the abovementioned limiting probabilities $\pi_{j}(j=0,1, \ldots, 7)$ of the placed Markov chain and the matrix $\mathbf{P}$ of the probabilities of transition from state $\mathrm{s}_{\mathrm{i}}$ to state $\mathrm{s}_{\mathrm{j}}$. This equation system has the following form:

$$
\left.\begin{array}{l}
{\left[\pi_{0}, \pi_{1}, \pi_{2}, \pi_{3}, \pi_{4}, \pi_{5}, \pi_{6}, \pi_{7}\right]=\left[\pi_{0} \pi_{1}, \pi_{2}, \pi_{3}, \pi_{4}, \pi_{5}, \pi_{6}, \pi_{7}\right] \cdot \mathbf{P}} \\
\sum_{\mathrm{k}=1}^{4} \pi_{\mathrm{k}}=1
\end{array}\right\}
$$


where, taking into account the fact that matrix (3) is the stochastic matrix, matrix $\mathbf{P}$ has the following form:

$$
\mathbf{P}=\left[\begin{array}{cccccccc}
0 & p_{01} & p_{02} & p_{03} & p_{04} & p_{05} & p_{06} & p_{07} \\
1 & 0 & 0 & 0 & 0 & 0 & 0 & 0 \\
1 & 0 & 0 & 0 & 0 & 0 & 0 & 0 \\
1 & 0 & 0 & 0 & 0 & 0 & 0 & 0 \\
1 & 0 & 0 & 0 & 0 & 0 & 0 & 0 \\
1 & 0 & 0 & 0 & 0 & 0 & 0 & 0 \\
1 & 0 & 0 & 0 & 0 & 0 & 0 & 0 \\
1 & 0 & 0 & 0 & 0 & 0 & 0 & 0
\end{array}\right]
$$

After solving the equation system (7) and making use of the formula (6) we get the following relations:

$$
\left.\begin{array}{l}
\mathrm{P}_{0}=\frac{\mathrm{E}\left(\mathrm{T}_{0}\right)}{\mathrm{E}\left(\mathrm{T}_{0}\right)+\sum_{\mathrm{l}=0}^{7} \mathrm{p}_{01} \mathrm{E}\left(\mathrm{T}_{1}\right)}, \mathrm{P}_{1}=\frac{\mathrm{p}_{01} \mathrm{E}\left(\mathrm{T}_{1}\right)}{\mathrm{E}\left(\mathrm{T}_{0}\right)+\sum_{\mathrm{l}=0}^{7} \mathrm{p}_{01} \mathrm{E}\left(\mathrm{T}_{1}\right)}, \\
\mathrm{P}_{2}=\frac{\mathrm{p}_{02} \mathrm{E}\left(\mathrm{T}_{2}\right)}{\mathrm{E}\left(\mathrm{T}_{0}\right)+\sum_{\mathrm{l}=0}^{7} \mathrm{p}_{01} \mathrm{E}\left(\mathrm{T}_{1}\right)}, \mathrm{P}_{3}=\frac{\mathrm{p}_{03} \mathrm{E}\left(\mathrm{T}_{3}\right)}{\mathrm{E}\left(\mathrm{T}_{0}\right)+\sum_{\mathrm{l}=0}^{7} \mathrm{p}_{01} \mathrm{E}\left(\mathrm{T}_{1}\right)}, \\
\mathrm{P}_{4}=\frac{\mathrm{p}_{04} \mathrm{E}\left(\mathrm{T}_{4}\right)}{\mathrm{E}\left(\mathrm{T}_{0}\right)+\sum_{\mathrm{l}=0}^{7} \mathrm{p}_{01} \mathrm{E}\left(\mathrm{T}_{1}\right)}, \mathrm{P}_{5}=\frac{\mathrm{p}_{05} \mathrm{E}\left(\mathrm{T}_{5}\right)}{\mathrm{E}\left(\mathrm{T}_{0}\right)+\sum_{\mathrm{l}=0}^{7} \mathrm{p}_{01} \mathrm{E}\left(\mathrm{T}_{1}\right)}, \\
\mathrm{P}_{6}=\frac{\mathrm{p}_{06} \mathrm{E}\left(\mathrm{T}_{6}\right)}{\mathrm{E}\left(\mathrm{T}_{0}\right)+\sum_{\mathrm{l}=0}^{7} \mathrm{p}_{01} \mathrm{E}\left(\mathrm{T}_{1}\right)}, \mathrm{P}_{7}=\frac{\mathrm{p}_{07} \mathrm{E}\left(\mathrm{T}_{7}\right)}{\mathrm{E}\left(\mathrm{T}_{0}\right)+\sum_{\mathrm{l}=0}^{7} \mathrm{p}_{01} \mathrm{E}\left(\mathrm{T}_{1}\right)}
\end{array}\right\}
$$

The probability $\mathrm{P}_{0}$ is the limiting probability that in a longer time interval of operation (theoretically for $t \rightarrow \infty$ ) the propulsion systems is in state $\mathrm{s}_{(0)}$. Thus this probability defines the serviceability of the system at arbitrary time $t$ of its operation, i.e. the ability of the system to perform a task. At the same time the probabilities $\mathrm{P}_{\mathrm{j}}(\mathrm{j}=1,2, \ldots, 7)$ are the limiting probabilities of the existence of states $s_{j} \in S$ of the analysed system when $t \rightarrow \infty$, i.e. the probabilities of the existence of situations when some system components (and, consequently, the entire system due to its series reliability structure) are in states of inability.

Calculating the probabilities $P_{0}$ and $P_{j}(j=1,2, \ldots, 7)$ requires assessing probabilities $\mathrm{p}_{\mathrm{ij}}$ and the expected values $E\left(T_{j}\right)$, which is expensive and time consuming.

Collecting the information necessary for assessing the above probabilities and expected values requires the use of relevant (SDG) systems to diagnose particular propulsion system elements, which are the diagnosed systems (SDN) in this case [5].

\section{FINAL REMARKS AND CONCLUSIONS}

The semi-Markov processes are becoming more and more frequently used for solving problems concerning reliability, general service and diagnostics of various devices, diesel engines for instance.

The use of the semi-Markov process, instead of the Markov process, as the model of reliability state changes of propulsion systems working on sea-going ships in a given time results from the fact that we have to expect that the random variable $\mathrm{T}_{(\mathrm{ij})}$ which represents the time interval when the system is in state $\mathrm{s}_{\mathrm{i}}$ given that the next state is $\mathrm{s}_{\mathrm{j}}$, and the random variable $\mathrm{T}_{\mathrm{i}}$ which is the time interval when the system is in state $\mathrm{s}_{\mathrm{i}}(\mathrm{i}=0,1$, $2, \ldots, 7)$ independently on what the next state is, have arbitrary concentrated distributions in set $\mathrm{R}_{+}=[0,+\infty)$. The use of the Markov process in this case would be justified when we could assume that the random variables $\mathrm{T}_{(\mathrm{ij})}$ and $\mathrm{T}_{\mathrm{i}}$ have exponential distributions.

The presented model is of certain practical importance, because of its easiness to estimate the transition probabilities $\mathrm{p}_{\mathrm{ij}}$ being the elements of matrix $\mathbf{P}(7)$ and the expected values $E\left(T_{j}\right)$. We should keep in mind here that the point estimation of the expected value $E\left(T_{j}\right)$ does not provide opportunities for assessing the accuracy of its estimation. This accuracy is only secured in the interval estimation, in which the confidence interval $\left[\mathrm{t}_{\mathrm{dj}}, \mathrm{t}_{\mathrm{gj}}\right]$ with random endpoints is calculated. This confidence interval contains the unknown expected value $E\left(T_{j}\right)$ with certain probability (confidence level) $\beta$.

The semi-Markov processes are stochastic processes which reveal specific properties. In publications on this subject different definitions of the semi-Markov process, with different levels of generality and precision levels, can be found. For the purpose of modelling the operation process of the ship propulsion system and other devices, the semi-Markov process (family of random variables) $\{\mathrm{W}(\mathrm{t}): \mathrm{t} \geq 0\}$, can be defined using a so-called uniform Markov regenerative process [11, $12,17]$.

It results from the definition of the semi-Markov process that it is the stochastic process with a discrete set of states, and its realisations are interval constant functions (having constant values in operating time intervals being the random variables), which are right-continuous. It also results from this definition that the process is well defined when its initial distribution $\mathrm{P}_{\mathrm{i}}=\mathrm{P}\left\{\mathrm{W}(0)=\mathrm{s}_{\mathrm{i}}\right\}$ is known, along with (in the analysed case) the functional matrix $\mathbf{Q}(\mathbf{t})=\left[\mathrm{Q}_{\mathrm{ij}}\right](\mathrm{i} \neq \mathrm{j} ; \mathrm{i}, \mathrm{j}=0,1,2, \ldots, 7)$, the elements of which are the probabilities of process transition from state " $\mathrm{s}_{\mathrm{i}}$ " to state " $\mathrm{s}_{\mathrm{j}}$ " in time not longer than $\mathrm{t}(4)$, being the non-decreasing functions of time $t$ and denoted as $Q_{i j}(t)$ $[1,6,11,12]$.

\section{BIBLIOGRAPHY}

1. Girtler J.: Applicability of semi-Markov processes as models of machine operation processes (in Polish). Machine Operation Issues (Zagadnienia Eksploatacji Maszyn), Warsaw 1996, z.3(107) pp. 419-428.

2. Girtler J.: Reliability model of two-shaft turbine combustion engine with heat regenerator. Journal of KONES Powertrain and Transport, Vol. 132, No. 4, 2006, pp.15-22.

3. Girtler J.: Possibility of defining theoretical operation for diesel engines in energy terms. Combustion Engines (Silniki Spalinowe), no. 3, 2011, pp. 1-9 [pdf].

4. Girtler J.: A method for evaluating the performance of a marine piston internal combustion engine used as the main engine on a ship during its voyage in different sailing conditions. Polish Maritime Research, Vol. 17 No. 4, 2010, pp. 31-38.

5. Girtler J.: Diagnostics as the condition for controlling the operation of marine internal combustion engines (in Polish). PNA studies, (Studia WSM) No. 28, Szczecin 1997.

6. Girtler J.: Physical aspects of application and usefulness of semi-Markov processes for modeling the processes occurring in operational phase of technical objects. Polish Maritime Research, Vol. 11, No 3, 2004, pp. 25-30.

7. Girtler J.: Quantum issues in diagnostics of marine energy machines and devices. Scientific Journals of the Maritime University of Szczecin. - No 30(102).

8. Girtler J.: Aspects of quantum diagnostics of machines (in Polish). XXXIX Machine Diagnostics Symposium. Wisla, $04 \div 10.03$. 2012, Materials issued as article abstracts and on CD, 23 p. Publications of the Faculty of Transport of the 
Silesian University of Technology (Wyd. Wydział Transportu Politechniki Ślaskiej), Katowice 2012.

9. Girtler J., Kitowski Z., Kuriata A.: Ship safety at sea. System approach (in Polish). WKiŁ, Warsaw1995.

10.Girtler J., Kuszmider S., Plewiński L.: Selected issues of sea-going ship operation in the aspect of safety of sailing. Monograph (in Polish). WSM, Szczecin 2003.

11.Grabski F.: Semi-Markov models of reliability and operation (in Polish). PAN IBS, Series: System Research (Badania Systemowe) vol. 30, Warsaw 2002.

12.Grabski F.: Theory of semi-Markov processes of technical object operation (in Polish). Scientific Reports of PNA (Zeszyty Naukowe AMW), no. 75A, Gdynia 1982.

13.Jadźwiński J., Borgoń J: Operating reliability and safety of flights (in Polish). WKiŁ, Warsaw 1989.

14.Kiliński A.: Descriptive and normative definitions of the idea of reliability (in Polish). Quality Issues (Problemy Jakości), No. 3, Warsaw 1972, pp.5-13.

15.Limnios N., Oprisan G.: Semi-Markov Processes and Reliability. Boston, Birkhauser 2001.

16.Piotrkowski I., Witkowski K.: Operation of marine internal combustion engines (in Polish). AM Gdynia 2002.

17.Сильвестров Д. С.: Полумарковские процессы с дискретным множеством состояний. Издательство „Советское Радио”. Москва, 1980.
18.Wojnowski W.: Marine power plants (in Polish). Part. I. PNA Publications (wyd. AMW), Gdynia 1998.

19.Wiśniewski B.: Wind undulation (in Polish). Scientific publications of SU (Wyd. Naukowe USz)., Szczecin 1998.

20. Machine diagnostics engineering (in Polish). Collective work, editors: B. Żółtowski and C. Cempel. PTDT. Wyd. ITE, Warsaw, Bydgoszcz, Radom 2004.

21.Reliability manual (in Polish). Collective work, editor: J. Migdalski. Publications of Machine Industry (Wydawnictwa Przemysłu Maszynowego) „WEMA”, Warsaw 1982

22. MAN B\&W Diesel A/S: CoCoS Maintenance, Designed for Maintenance Excellence, Copenhagen 2005.

23.Wartsila Corporation: Service News from Wartsila Corporation 2 2002/1 2003, CBM for two stroke engines, Kaidara Software, Wartsila Corporation Helsinki, March 2003.

\section{CONTACT WITH THE AUTHOR}

Jerzy Girtler, Prof.

Department of Ship Power Plants

Faculty of Ocean Engineering and Ship Technology Gdansk University of Technology

Narutowicza 11/12

80-233 Gdansk, POLAND

e-mail: jgirtl@pg.gda.pl 